\title{
Quantitative methods for somatosensory evaluation in atypical odontalgia
}

\section{André Luís PORPORATTI(a) Yuri Martins COSTA(a) Juliana STUGINSKI-BARBOSA(a) Leonardo Rigoldi BONJARDIM(b) Paulo César Rodrigues CONTI(a) Peter SVENSSON(c)}

(a) Universidade de São Paulo - USP, Bauru School of Dentistry, Department of Prosthodontics, Bauru, SP, Brazil.

(b) Universidade de São Paulo - USP, Bauru School of Dentistry, Department of Biological Sciences, Bauru, SP, Brazil.

(c)Aarhus University, Department of Dentistry, Section of Clinical Oral Physiology, Aarhus, Denmark.
Declaration of Interests: The authors certify that they have no commercial or associative interest that represents a conflict of interest in connection with the manuscript.

\section{Corresponding Author:}

Yuri Martins Costa

E-mail: yurimartinscosta@yahoo.com.br

DOI: 10.1590/1807-3107BOR-2015.vol29.0020

Submitted: Jul 07, 2014

Accepted for publication: Sep 17, 2014

Last revision: Nov 28, 2014
Abstract: A systematic review was conducted to identify reliable somatosensory evaluation methods for atypical odontalgia $(\mathrm{AO})$ patients. The computerized search included the main databases (MEDLINE, EMBASE, and Cochrane Library). The studies included used the following quantitative sensory testing (QST) methods: mechanical detection threshold (MDT), mechanical pain threshold (MPT) (pinprick), pressure pain threshold (PPT), dynamic mechanical allodynia with a cotton swab (DMA1) or a brush (DMA2), warm detection threshold (WDT), cold detection threshold (CDT), heat pain threshold (HPT), cold pain detection (CPT), and/or wind-up ratio (WUR). The publications meeting the inclusion criteria revealed that only mechanical allodynia tests (DMA1, DMA2, and WUR) were significantly higher and pain threshold tests to heat stimulation (HPT) were significantly lower in the affected side, compared with the contralateral side, in AO patients; however, for MDT, MPT, PPT, CDT, and WDT, the results were not significant. These data support the presence of central sensitization features, such as allodynia and temporal summation. In contrast, considerable inconsistencies between studies were found when AO patients were compared with healthy subjects. In clinical settings, the most reliable evaluation method for $\mathrm{AO}$ in patients with persistent idiopathic facial pain would be intraindividual assessments using HPT or mechanical allodynia tests.

Keywords: Causalgia; Toothache; Review.

\section{Introduction}

Atypical odontalgia (AO) is a rare chronic orofacial condition that represents a real challenge for the dentists. ${ }^{1}$ These patients feel continuous and severe pain in the tooth or in the dentoalveolar region, in the absence of identifiable odontogenic pathology. ${ }^{2,3}$ As such, $\mathrm{AO}$ was classified as a type of persistent idiopathic facial pain by the International Headache Society (IHS). ${ }^{4}$ The incidence of $\mathrm{AO}$ is $3 \%-6 \%$ among patients undergoing endodontic treatment. ${ }^{5,6}$ Dental treatments like endodontics can damage or sever nerve fibers, leading to a perturbation or interruption of peripheral afferent impulses. The somatosensory deficit caused by deficient afferent impulses is known as deafferentation. Accordingly, $\mathrm{AO}$ was tentatively described as neuropathic pain because of the potential involvement of nerve damage. ${ }^{7}$

Several mechanisms are involved in the pathophysiology of AO. First, the higher density in sodium channels in the regenerating nerve 
endings leads to enhanced firing of action potentials, and an ephaptic transmission of nerve impulses to the trigeminal spinal subnucleus caudalis. ${ }^{8}$ Second, the higher frequency of action potentials firing from the first order to the second order neuron, and the release of neurotransmitters, may lead to a central sensitization process in the central nervous system (CNS). Finally, a deficiency in the endogenous modulatory control of pain can contribute to the facilitation and maintenance of pain. ${ }^{9}$ These processes are expressed clinically as somatosensory abnormalities such as allodynia, hyperalgesia, and pain exacerbation by thermal, mechanical, and/or chemical stimuli. ${ }^{10,11}$

Quantitative sensory testing (QST) was developed to assess the presence and severity of somatosensory abnormalities in patients with neuropathic pain., ${ }^{712} \mathrm{~A}$ research team recently published recommendations to standardize the evaluation of somatosensory function for orofacial pain conditions, and to allow data comparison between studies. ${ }^{13}$ However, the usefulness and applicability of each QST method for the examination of $\mathrm{AO}$ patients remains undefined. Therefore, a systematic review was conducted to identify the most reliable quantitative QST method for the somatosensory evaluation of $\mathrm{AO}$ patients.

\section{Methodology Search Strategy}

The articles of interest used a specific QST method to evaluate $\mathrm{AO}$ patients, and included data analysis. The relevant articles were identified by searching the databases PubMed, LILACS, Cochrane (including Central Cochrane), and Current Controlled Trials, from January 1990 to August 2011, in the English, Portuguese, or Spanish languages. The keywords used were as follows: atypical odontalgia OR deafferentation pain in teeth OR phantom toothache AND sensory abnormalities OR sensory test OR quantitative sensory testing OR QST. In addition, a manual search was performed for the most relevant journals (Pain, Journal of Pain, European Journal of Pain, Journal of Oral Rehabilitation, Journal of Orofacial Pain, and Headache).

\section{Inclusion criteria}

The studies included were randomized controlled trials, cohort studies, clinical trials, case-control studies, and cross-sectional studies, describing the following QST methods: mechanical detection threshold (MDT), mechanical pain threshold (MPT) (pinprick), pressure pain threshold (PPT), dynamic mechanical allodynia with a cotton swab (DMA1) or a brush (DMA2), warm detection threshold (WDT), cold detection threshold (CDT), heat pain threshold (HPT), cold pain detection (CPT), or wind-up ratio (WUR). ${ }^{14,15,16}$ These methods were previously described in detail by Svensson et al. ${ }^{13}$ Case-reports and literature reviews were excluded.

The inclusion criteria was AO subjects aged 18-85 years fulfilling the following diagnostic criteria: $: 3,17,18$ a. Persistent pain $\geq 8$ hours per day, during $\geq 15$ days or more per month, and for $\geq 3$ months;

b. Pain localized to the dento-alveolar area, where the maximum pain is confined within an anatomical area;

c. Pain not caused by another disease or disorder, dental, neurological examination, or imaging.

\section{Data Collection}

Three independent reviewers selected and analyzed the articles. Disagreements between reviewers on the selection criteria were resolved through a discussion on the article content until a consensus was reached.

\section{Critical Appraisal}

After selecting the papers, the study designs and characteristics were extracted. The diagnostic tools QUADRAS, CASP, and Analysis of Needs were not used ${ }_{1}^{19}$ because the use of QST methods for diagnostic purposes needs further validation. ${ }^{20}$ However, we used a critical appraisal tool adapted from Thomas et al. ${ }^{21}$ This tool analyses 5 criteria: study design, objective and methodology criteria, sample size, internal and external validity, and statistical tests. The quality of each study was rated using the following scoring system applied to each criterion: (E) Excellent, $(G)$ Good, (R) Regular, or (X) Excluded. Each study was globally then rated as strong, moderate, or weak. 


\section{Results}

An initial search identified 46 potentially relevant studies. After abstract analysis, 36 studies were excluded, because they did not meet the inclusion criteria (Figure 1). Full-text examination of the remaining 10 studies indicated that 6 of them did not fulfill the inclusion criteria (Table 1). Thus, four studies were included in this systematic review.

The characteristics and quality evaluation of the 4 included studies are shown in Table 2. All 4 studies were evaluated as "Strong" on the basis of the quality criteria. One study was conducted in the United States, ${ }^{10}$ two in Sweden, ${ }^{11,22}$ and one in Denmark. ${ }^{23}$ The articles were published from 2006 to 2011. In total, 112 AO patients were evaluated (mean: 28 subjects; range: 10-46), predominantly women (83\%), with a mean age of 54.3 years. The mean duration of pain was 7.9 years, with a higher prevalence of $\mathrm{AO}$ in the maxilla (62\%).

The diagnostic criteria for $\mathrm{AO}$ were similar in all studies: (1) pain in the tooth or in a corresponding region; (2) continuous or nonparoxysmal; (3) pain duration between $4^{10}$ and 6 months; $;^{11,22,23}$ and (4) the absence of dental pathology detected by clinical examination or imaging. In all the included AO patients, pain started after some process of deafferentation, like endodontic therapy or tooth extraction. In all studies, periapical and/or panoramic examination was performed as a complementary image evaluation for differential diagnosis. One

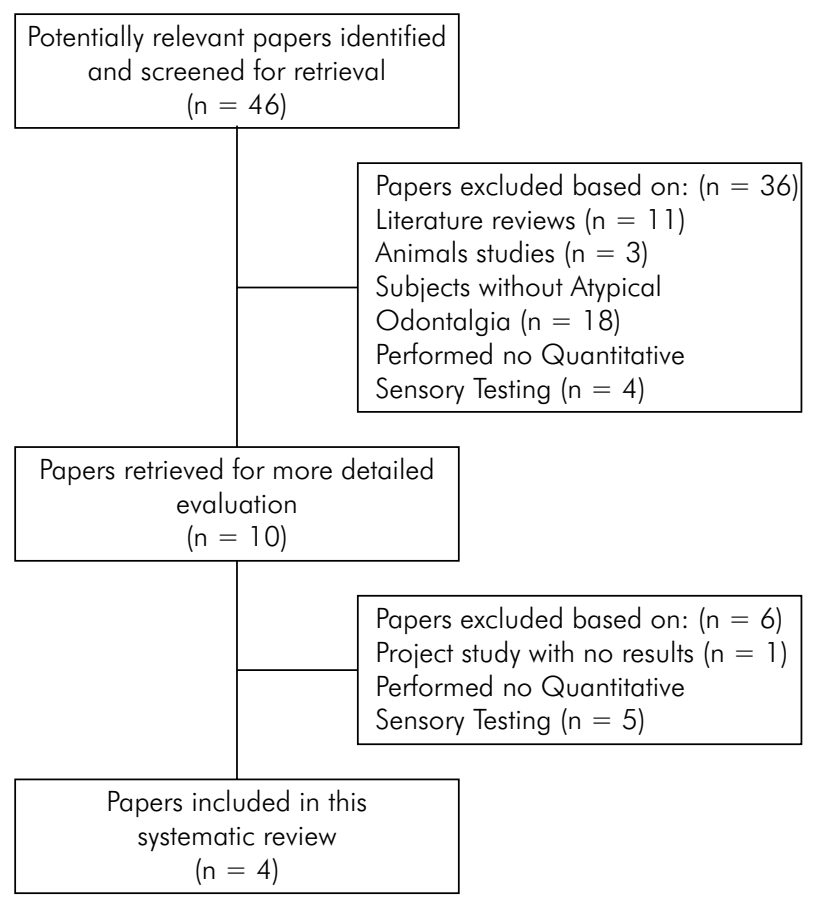

Figure 1. Flow diagram of the selection process for this systematic review.

paper included additional diagnostic criteria for $\mathrm{AO}$ as burning or throbbing pain in the tooth or in corresponding region. ${ }^{10}$

Regarding QST evaluation, none of the studies performed all the tests (Table 3). ${ }^{11,22}$ However, they all included control data involving either the contralateral

Table 1. Rationale for article exclusion after full-text reading.

\begin{tabular}{|c|c|}
\hline Paper & Reason \\
\hline $\begin{array}{l}\text { Jensen TS. Sensory examination and pharmacological modulation of oral } \\
\text { hyperexcitability in patients with atypical odontalgia and matched healthy } \\
\text { controls. } 2005 .\end{array}$ & $\begin{array}{l}\text { Evaluation based on magnetic resonance imaging and } \\
\text { the dynamic pressure detection threshold detected with an } \\
\text { intraoral instrument. }\end{array}$ \\
\hline $\begin{array}{l}\text { Moana-Filho EJ, Nixdorf DR, Bereiter DA, John MT, Harel N. Evaluation of a } \\
\text { magnetic resonance-compatible dentoalveolar tactile stimulus device. BMC } \\
\text { Neurosci. } 2010 \text { Oct } 28 ; 11: 142 \text {. }\end{array}$ & No results shown. \\
\hline $\begin{array}{l}\text { Baad-Hansen L, List T, Jensen TS, Svensson P. Increased pain sensitivity to } \\
\text { intraoral capsaicin in patients with atypical odontalgia. J Orofac Pain. } 2006 \\
\text { Spring;20(2):107-14. }\end{array}$ & Evaluation based on electrical and chemical stimulation tests. \\
\hline
\end{tabular}




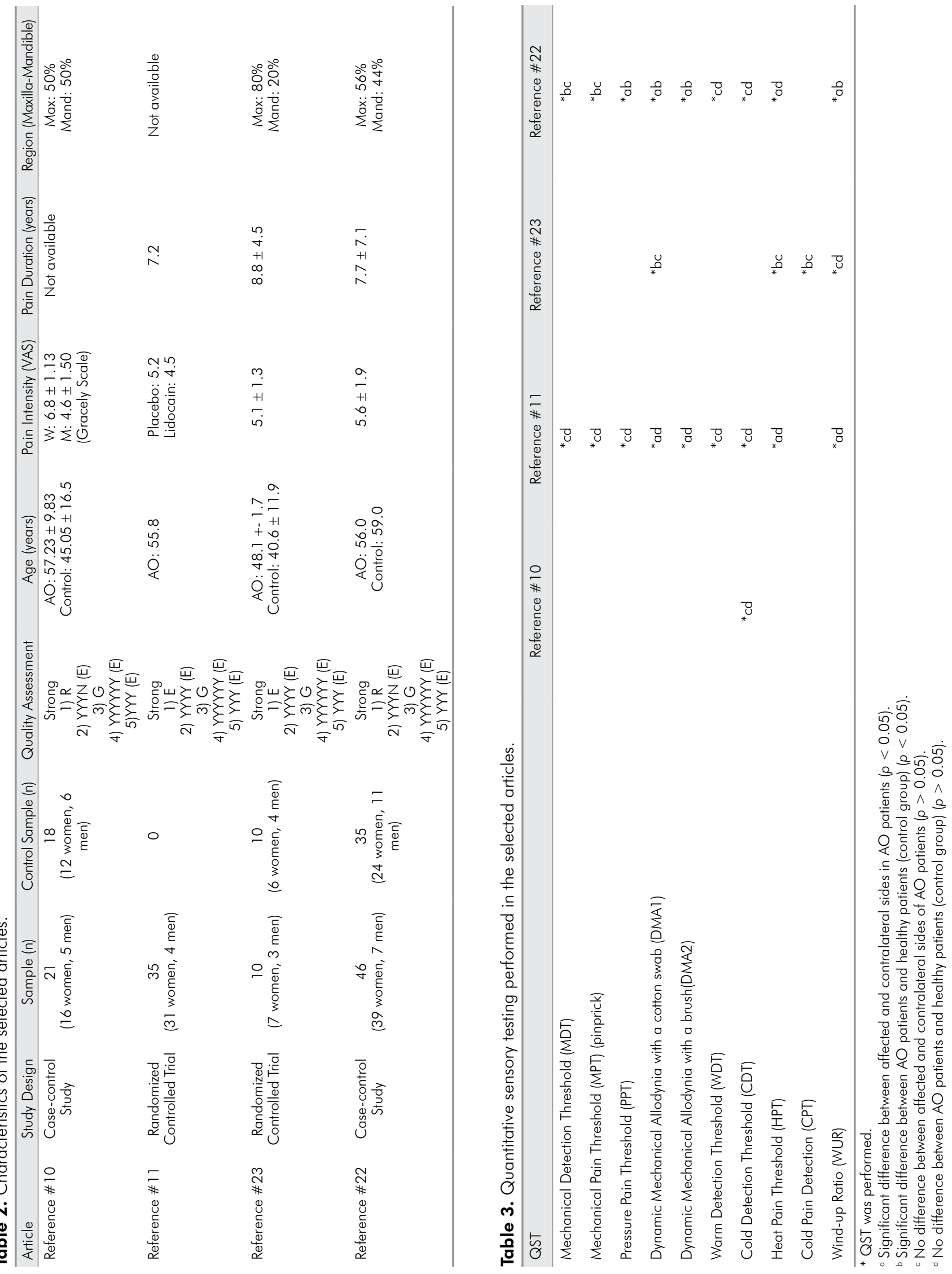


side of the same $\mathrm{AO}$ patients and/or a group of healthy participants. ${ }^{10,11,22,23}$ In all cases, pain intensity was measured with a Visual Analogue Scale (VAS).

During contralateral comparisons, pain intensity was significantly higher with dynamic mechanical tests conducted at constant and identical stimulus intensity (DMA1, DMA2, and WUR). Among the thermal tests, HPT generated a significantly lower pain threshold than CDT and WDT. However, there was no significant difference between MDT, MPT, PPT, WDT, and CDT. Finally, CPT was not performed in any study. Regarding group comparisons, $\mathrm{AO}$ patients showed significantly higher pain thresholds with DMA1, DMA2, MDT, MPT, PPT, and CPT than a group of healthy individuals. The results of WUR and HPT were inconclusive because only one study showed significant differences. In addition, there was no significant difference between $\mathrm{AO}$ patients and control subjects for WDT and CDT.

\section{Discussion}

This systematic review emphasizes the reliability of the dynamical mechanical tests DMA1, DMA2, and WUR, and the thermal test HPT, for the somatosensory evaluation of AO patients. Additional QSTs appear to be helpful when the patients were compared to healthy controls, such as mechanical tests (DMA1, DMA2, MDT, MPT, and PPT) and thermal tests (HPT). The 4 included studies specially indicated the following: (1) studies evaluating AO with QST are recent; (2) the scientific quality of the papers are consistently high; (3) the diagnostic criteria for $\mathrm{AO}$ were similar and all AO patients previously undergone dental therapy; (4) mechanical allodynia and pain threshold to heat stimulation were significantly different in $\mathrm{AO}$ patients than in healthy subjects; (5) there are inconsistencies between studies regarding pain thresholds detected by mechanical pressure and thermal detection; and (6) methodological problems were encountered in the studies comparing $\mathrm{AO}$ patients with healthy subjects.

A few controlled studies investigated the relationship between somatosensory abnormalities in AO patients. Although a critical evaluation for QST studies is currently not available, the questionnaire adapted from Thomas et al. ${ }^{21}$ was useful to select and evaluate the studies, thus contributing to the methodology excellence. This tool was adapted because the selected studies were not all clinical trials, and the questionnaire from Thomas et al. ${ }^{21}$ also allows the evaluation of clinical observational studies accounting for 2 of the 4 selected studies.

This systematic review revealed that $\mathrm{AO}$ is more frequent in women than men, and that maxilla is the most prevalent affected region, which is consistent with epidemiological studies. ${ }^{5,24,25}$ Women are more likely to suffer a variety of recurrent pains, and to express greater pain intensity than men. ${ }^{26}$ The underlying mechanism remains poorly understood, but possible factors include sex hormones, genetic variants, emotions, and menstrual cycle..$^{26,27}$

The periapical and panoramic radiographic techniques have been used as parameters for the radiographic examination. It was recently noticed that the use of Cone Bean Computed Tomography (CBCT) in patients with suspected $\mathrm{AO}$ improves the differentiation between $\mathrm{AO}$ and Symptomatic Apical Periodontitis (SAP) in patients with chronic intraoral pain. It was reported in an additional $17 \%$ of periapical bone destruction in CBCT compared with the conventional radiography. ${ }^{28}$

Somatosensory abnormalities are common features in patients with suspected neuropathic pain like AO, and QST is a helpful tool to evaluate these cases. ${ }^{14}$ Among them, dynamic mechanical tests (DMA1, DMA2, and WUR) determine the presence of allodynia. They activate low-threshold mechanoreceptors and forward impulses through the nerve fiber $\mathrm{A} \beta$ to the $\mathrm{CNS}$, which can trigger a cascade of events and increase neural excitability in the caudal subnucleus of trigeminal nerve. Therefore, these tests reflect the presence of a central sensitization process in $\mathrm{AO}$ patients. In clinical settings, they are conducted by brushing the bristles of a toothbrush or a cotton swab on the painful area. The contralateral side is commonly used as a control to assess somatosensory changes in pain intensity. In this review, DMA1, DMA2, and WUR all generated significantly higher pain intensities on the affected side than on the contralateral side of AO patients. ${ }^{15}$ In contrast, none of the static mechanical QSTs (MDT, MPT, and PPT) showed significant differences in pain threshold between affected and control areas. Although touch and pressure sensations are often 
classified as distinct, they are detected by the same receptors on the Meissner and Pacine Corpuscle and Merkel Discs. ${ }^{29}$ Taken together, these data indicate that peripheral nerve impulses alone cannot explain the constant pain of these patients, ${ }^{11}$ suggesting an amplification of the nociceptive pathways.

Temperature variations can be discriminated by at least three sensory receptors, which cold, heat, and pain receptors. Nerve impulses are sent to the CNS through C fibers for heat and through Aס fibers for cold. In contrast, pain receptors (nociceptors) are free nerve endings stimulated by excessive heat or cold, which are evaluated by thermal pain threshold tests (HPT or CPT). On the other hand, thermal detection tests (CDT or WDT) activate different receptors, which probably justify the different results from these tests in the review. ${ }^{29}$ In the present review, the only thermal QST that detected significant differences in pain threshold between the affected area and the contralateral side of AO patients was HPT, thereby supporting the involvement of central sensitization and temporal summation. Temporal summation is related to constant and repeated C fiber nociceptive stimulation, resulting in exaggerated and amplified afferent inputs to the subnucleus caudalis of the trigeminal brain stem sensory nuclear complex. ${ }^{15}$

There were major inconsistencies between studies comparing the QST data of AO patients and healthy

\section{References}

1. Baad-Hansen L, Leijon G, Svensson P, List T. Comparison of clinical findings and psychosocial factors in patients with atypical odontalgia and temporomandibular disorders. J Orofac Pain. 2008 Winter;22(1):7-14.

2. Melis M, Lobo SL, Ceneviz C, Zawawi K, Al-Badawi E, Maloney $\mathrm{G}$, et al. Aty pical odontalgia: a review of the literature. Headache. 2003 Nov-Dec;43(10):1060-74.

3. Woda A, Pionchon P. A unified concept of idiopathic orofacial pain: clinical features. J Orofac Pain. 1999 Summer;13(3):172-84; discussion 185-95.

4. Classification and diagnostic criteria for headache disorders, cranial neuralgias and facial pain. Headache Classification Committee of the International Headache Society. Cephalalgia. 1988;8 Suppl 7:1-96.

5. Vickers ER, Cousins MJ, Walker S, Chisholm K. Analysis of 50 patients with atypical odontalgia. A preliminary report on pharmacological procedures for diagnosis and treatment. Oral Surg Oral Med Oral Pathol Oral Radiol Endod. 1998 Jan;85(1):24-32. subjects. In fact, QSTs are psychophysical assessments, whereby the perception a painful stimulus is affected by individual characteristics such as psychosocial, emotional, and cultural factors. ${ }^{30,31}$ The results of QSTs would accordingly be associated with higher interindividual variability than contralateral variability in the same patient. Therefore, the most reliable methodology would be individual QSTs applied to the affected and unaffected sides of the AO patients. However, this paradigm only applies if the contralateral side is indeed unaffected.

The main limitation for this systematic review was the small number of articles selected on the basis of the stringent inclusion and exclusion criteria, which was inevitable for such a new field of research.

\section{Conclusion}

This systematic review supports a role for CNS sensitization in the somatosensory abnormalities of $\mathrm{AO}$ patients. The most reliable evaluation method by QSTs would be a bilateral comparison of pain thresholds using mechanical allodynia (DMA1, DMA2, and WUR) and/or heat pain threshold (HPT) tests.

\section{Acknowledgements}

Fundação de Amparo à Pesquisa do Estado de São Paulo - FAPESP (grant 2011/14915-5).
6. Campbell RL, Parks KW, Dodds RN. Chronic facial pain associated with endodontic therapy. Oral Surg Oral Med Oral Pathol. 1990 Mar;69(3):287-90.

7. Baad-Hansen L. Atypical odontalgia - pathophysiology and clinical management. J Oral Rehabil. 2008 Jan;35(1):1-11.

8. Baumgartner U, Magerl W, Klein T, Hopf HC, Treede RD. Neurogenic hyperalgesia versus painful hypoalgesia: two distinct mechanisms of neuropathic pain. Pain. 2002 Mar;96(1-2):141-51.

9. Benoliel R, Sharav Y, Tal M, Eliav E. Management of chronic orofacial pain: today and tomorrow. Compend Contin Educ Dent. 2003 Dec;24(12):909-20, 922-4, 926-8 passim; quiz 932.

10. Zagury JG, Eliav E, Heir GM, Nasri-Heir C, Ananthan S, Pertes R, et al. Prolonged gingival cold allodynia: a novel finding in patients with atypical odontalgia. Oral Surg Oral Med Oral Pathol Oral Radiol Endod. 2011 Mar;111(3):312-9.

11. List T, Leijon G, Helkimo M, Oster A, Svensson P. Effect of local anesthesia on atypical odontalgia--a randomized controlled trial. Pain. 2006 Jun;122(3):306-14. 
12. Pigg M, Baad-Hansen L, Svensson P, Drangsholt M, List T. Reliability of intraoral quantitative sensory testing (QST). Pain. 2010 Feb;148(2):220-6.

13. Svensson P, Baad-Hansen L, Pigg M, List T, Eliav E, Ettlin $\mathrm{D}$, et al. Guidelines and recommendations for assessment of somatosensory function in oro-facial pain conditions--a taskforce report. J Oral Rehabil. 2011 May;38(5):366-94.

14. Cruccu G, Anand P, Attal N, Garcia-Larrea L, Haanpää M, Jørum E, et al. EFNS guidelines on neuropathic pain assessment. Eur J Neurol. 2004 Mar;11(3):153-62.

15. Walk D, Sehgal N, Moeller-Bertram T, Edwards RR, Wasan A, Wallace M, et al. Quantitative sensory testing and mapping: a review of nonautomated quantitative methods for examination of the patient with neuropathic pain. Clin J Pain. 2009 Sep;25(7):632-40.

16. Backonja MM, Walk D, Edwards RR, Sehgal N, MoellerBertram T, Wasan A, et al. Quantitative sensory testing in measurement of neuropathic pain phenomena and other sensory abnormalities. Clin J Pain. 2009 Sep;25(7):641-7.

17. Graff-Radford SB, Solberg WK. Atypical odontalgia. J Craniomandib Disord. 1992 Fall;6(4):260-5.

18. Nixdorf DR, Drangsholt MT, Ettlin DA, Gaul C, De Leeuw $R$, Svensson P, et al. Classifying orofacial pains: a new proposal of taxonomy based on ontology. J Oral Rehabil. 2012 Mar;39(3):161-9.

19. Pfau DB, Geber C, Birklein F, Treede RD. Quantitative sensory testing of neuropathic pain patients: potential mechanistic and therapeutic implications. Curr Pain Headache Rep. 2012 Jun;16(3):199-206.

20. Baldwin C, Grimmer K, et al. Critical Appraisal Tools Page [Internet]. Adelaide, (South Australia): International Centre for Allied Health Evidence; 2011. Available from:http:// www.unisa.edu.au/research/sansom-institute-for-healthresearch/research-at-the-sansom/research-concentrations/ allied-health-evidence/resources/cat/
21. Thomas BH, Ciliska D, Dobbins M, Micucci S. A process for systematically reviewing the literature: providing the research evidence for public health nursing interventions. Worldviews Evid Based Nurs. 2004;1(3):176-84.

22. List T, Leijon G, Svensson P. Somatosensory abnormalities in atypical odontalgia: A case-control study. Pain. 2008 Oct;139(2):333-41.

23. Baad-Hansen L, Juhl GI, Jensen TS, Brandsborg B, Svensson P. Differential effect of intravenous S-ketamine and fentan$\mathrm{yl}$ on atypical odontalgia and capsaicin-evoked pain. Pain. 2007 May;129(1-2):46-54.

24. Madland G, Feinmann C. Chronic facial pain: a multidisciplinary problem. J Neurol Neurosurg Psychiatry. 2001 Dec;71(6):716-9.

25. Stuginski-Barbosa J. Odontalgia atípica: características clínicas, diagnóstico diferencial e tratamento. Rev Dor. 2006 Jan-Mar;7(1):729-34.

26. Girard-Tremblay L, Auclair V, Daigle K, Leonard G, Whittingstall K, Goffaux P. Sex differences in the neural representation of pain unpleasantness. J Pain. 2014 Aug;15(8):867-77.

27. Goffaux P, Michaud K, Gaudreau J, Chalaye P, Rainville P, Marchand S. Sex differences in perceived pain are affected by an anxious brain. Pain. 2011 Sep;152(9):2065-73.

28. Pigg M, List T, Petersson K, Lindh C, Petersson A. Diagnostic yield of conventional radiographic and cone-beam computed tomographic images in patients with atypical odontalgia. Int Endod J. 2011 Dec;44(12):1092-101.

29. Johnson KO. The roles and functions of cutaneous mechanoreceptors. Curr Opin Neurobiol. 2001 Aug;11(4):455-61.

30. Pavlakovic G, Petzke F. The role of quantitative sensory testing in the evaluation of musculoskeletal pain conditions. Curr Rheumatol Rep. 2010 Dec;12(6):455-61.

31. Melzack R, Wall PD. The psychology of pain. 2nd ed. London: Penguin Books; 1991, c1988. The Challenge of Pain. p. 15-33. 